\title{
Synthesis, optical properties and application of a set of novel pyrazole nopinone
}

derivatives

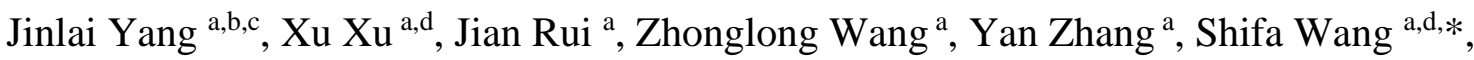
Liangru $\mathrm{Wu}^{\mathrm{b}, \mathrm{c}, *}$

${ }^{a}$ College of Chemical Engineering, Nanjing Forestry University, Nanjing, Jiangsu 210037, People's Republic of China

${ }^{b}$ China National Bamboo Research Center, Hangzhou 310012, Zhejiang, China

${ }^{c}$ Key Laboratory of High Efficient Processing of Bamboo of Zhejiang Province, Hangzhou 310012, Zhejiang, China

dJiangsu Key Lab of Biomass-based green Fuels and Chemicals, Nanjing 210037, People's Republic of China

*Corresponding author: Dr. and Prof. Shifa Wang

Institute of Chemical Engineering, Nanjing Forestry University, Nanjing, Jiangsu 210037, People's Republic of China

Jiangsu Key Lab of Biomass-based green Fuels and Chemicals, Nanjing, Jiangsu 210037, People's Republic of China

Phone: +86-25-85427812; Fax: +86-25-85427812

Email: wangshifa65@163.com 


\begin{abstract}
Pyrazole derivatives (4-6) were directly synthesized from $\beta$-pinene derivative nopinone, and they were characterized by Fourier transform infrared (FTIR) spectoscope, nuclear magnetic resonance (NMR), and mass spectrometry. Their optical properties were investigated by ultraviolet-visible spectroscopy and fluorescence spectroscopy. The three compounds emitted strong blue fluorescence in ethanol. Using a fluorescence quenching method, compound $\mathbf{4}$ could be used to detect the content (100.57\%) of copper sulfate pentahydrate ( $\geq 99 \%)$ with a RSD of $1.98 \%, y=-$ $0.1127 x+2.7148, R^{2}=0.9703\left(\mathrm{Cu}^{2+}: 0.5-8.0 \times 10^{-5} \mathrm{~mol} / \mathrm{L}\right)$, and compounds 4-6 also had utility of calculating the content of anhydrous ferric chloride at a wide range of concentration. Thus, compounds 4-6 are new functional fluorescents for detecting the content of some purchased products.
\end{abstract}

Keywords: Nopinone; Pyrazole derivative; Fluorescence quenching; Detection 


\section{Introduction}

Recently, the fluorescence chemosensors for selectively detecting heavy metal ions have been paid much attention due to their potential applications [1-4]. Thus, many fluorescent compounds have been synthesized for a good detection of $\mathrm{Cu}^{2+}$ and $\mathrm{Fe}^{3+}$ ions. 3-Acetoacetyl-7-hydroxycoumarin was synthesized and used as a highly sensitive onoff fluorescent chemosensor for $\mathrm{Cu}^{2+}$ ion [5], while a two-photon fluorescent probe based on dansyl moiety was synthesized for detecting $\mathrm{Cu}^{2+}$ with a low detection limit [6]. At the same time, ethyl-2-(2-aminothiazol-4-yl)-2-(hydroxyimino)acetate was first introduced into a fluorescent probe and exhibited fluorescence enhancement for identifying $\mathrm{Fe}^{3+}$ ion [7], and phenanthro[9,10-d]imidazole-coumarin derivatives represented the selective "turn-off" fluorescence phenomenon for $\mathrm{Fe}^{3+}$ [8]. Furthermore, there were some new synthesized compounds with a function of detecting two ions of $\mathrm{Cu}^{2+}$ and $\mathrm{Fe}^{3+}$, such as $\pi$-extend tetrathiafulvalene derivative [9], tetraphenylethylene based fluorescent chemosensor (RbTPE) [10], naphthalenediimide based probe [11], fluorenylidene bridged 2-naphthylamine substituted cyclotriphosphazenes [12], etc. Because of their utility, novel organic fluorescent probes for $\mathrm{Cu}^{2+}$ and $\mathrm{Fe}^{3+}$ ions are also urgently needed.

$\beta$-pinene is a main constituent of natural turpentine, and nopinone was directly obtained by oxidating $\beta$-pinene with potassium permanganate [13]. Nopinone is easy to develop new derivatives because of its $\mathrm{C}=\mathrm{O}$ group [14,15], and many nopinone derivatives have been reported [16-19], such as alkylation derivatives of nopinone [20], chiral annulated indenes [21], nopinone triazole ketones [22], pyridine derivatives of pinene [23], chiral 1,3-aminoalcohols and 1,3-diols [24], 4-pyridyl-2-aminopyrimidine derivatives [25], etc. In addition, some novel nopinone derivatives have been 
synthesized for a functional application in recent years. Two useful ketene hydroxybenzylidene nopinone derivatives were provided for an application on acid-base indicator [26], and nopinone derivatives could further be used in fluorescent materials. Quinazolin-2-amine nopinone derivatives were successfully synthesized for using in cellular fluorescence imaging [27], while a novel tetrahydroquinazolin-2-amine-based high selective fluorescent sensor for $\mathrm{Zn}^{2+}$ was prepared from nopinone [28]. Thus, luminescent materials synthesized from nopinone have a promising potential for application, to develop more fluorescent materials based on nopinone is very meaningful for the utilization of turpentine.

In this paper, we report three novel pyrazole derivatives (1-3) synthesized from nopinone, and their optical properties were fully studied in the solution state. Among them, compound $\mathbf{1}$ could be used to detect $\mathrm{Cu}^{2+}$ and $\mathrm{Fe}^{3+}$ ions by using a fluorescence quenching way, and the other two were a "turn-off" fluorescence probe for $\mathrm{Fe}^{3+}$ ion.

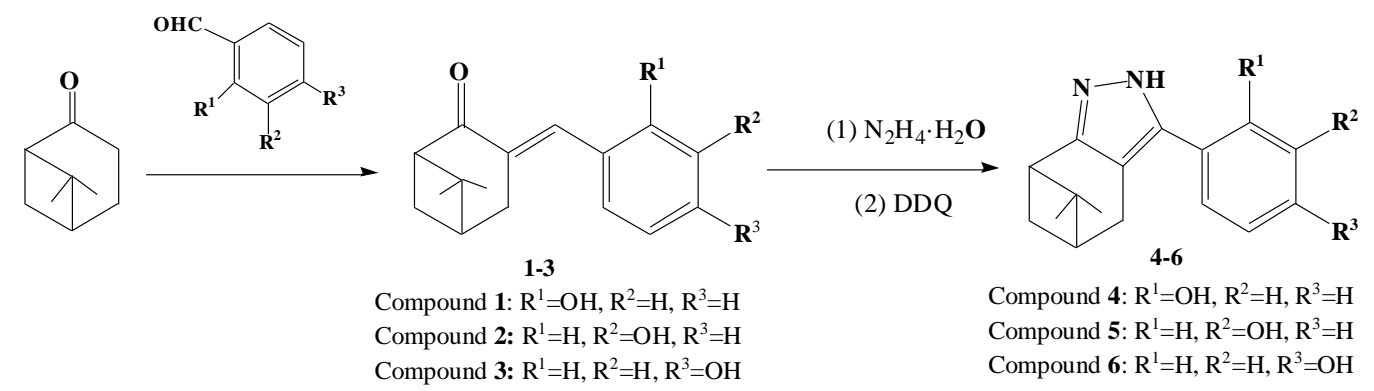

Scheme 1. Synthesis of pyrazole nopinone derivatives (4-6)

\section{Experimental}

\subsection{Materials and instruments}

Reagents and solvents were purchased from commercial suppliers and used without further purification. All reactions were monitored by GC (America Agilent 7890A). Mass spectra were obtained on the America Agilent 5975c mass spectrometer. The ${ }^{1} \mathrm{H}$ and ${ }^{13} \mathrm{C}-\mathrm{NMR}$ spectra were recorded on a Bruker AV-300 spectrometer operating at 
frequencies of $300 \mathrm{MHz}(\mathrm{H})$ and $75 \mathrm{MHz}(\mathrm{C})$. The IR spectra $v / \mathrm{cm}^{-1}(\mathrm{KBr})$ were recorded on Nicolet 380 FT-IR infrared spectrometer. Melting points were measured using X-6 microscopic melting point apparatus. The UV-visible absorption spectra were measured on a UV-2450 spectrophotometer (SHIMADZU) using a quartz cuvette having $1 \mathrm{~cm}$ path length. The fluorescence spectra were determined on a PerkinElmer LS 55 fluorescence spectrophotometer, excitation wavelength at $260 \mathrm{~nm}$, scan from 300 $\mathrm{nm}$ to $450 \mathrm{~nm}$ with a $100 \mathrm{~nm} / \mathrm{min}$ of scan speed. Thermal gravimetric analysis (TGA) was conducted on a Shimadzu thermal analyzer (DTG-60AH). The samples were heated under a nitrogen stream of $100 \mathrm{~mL} / \mathrm{min}$ with a heating rate of $10^{\circ} \mathrm{C} / \mathrm{min}$.

\subsection{Synthesis}

Compounds 1-3 were first synthesized by a condensation reaction from nopinone by a reported method [26], then compounds 4-6 were further synthesized through two steps, as shown in Scheme 1. These novel compounds were characterized by IR, MS, and HRMS, and these analyses confirmed compounds 4-6 to be pyrazole nopinone derivatives.

\subsubsection{6,6-Dimethyl-3-(2'-hydroxyphenyl)-4,5,6,7-tetrahydro-2H-5,7-methano-indazole}

(4). A $250 \mathrm{~mL}$ dried three-necked flask equipped with a thermometer, stirrer and condenser was charged with 3-(2'-hydroxybenzylidene)nopinone 1 (5 mmol) and hydrazine hydrate $(6 \mathrm{mmol})$ in $30 \mathrm{~mL}$ of ethanol. The resulting mixture was refluxed for $15 \mathrm{~h}$ until the conversion ratio of 3-(2'-hydroxybenzylidene)nopinone reached over $95 \%$ (monitored with GC). After the solvent was removed, the system was added with 1,4dioxane $(70 \mathrm{ml})$ and 2,3-dichloro-5,6-dicyano-1,4-benzoquinone (DDQ, $5.5 \mathrm{mmol})$ to another refluxed reaction for $18 \mathrm{~h}$. After adding $15 \mathrm{ml}$ potassium hydroxide solution (20\%) and $40 \mathrm{ml}$ dichloromethane, the reacted mixture was stirred for $30 \mathrm{~min}$, then it 
was extracted with dichloromethane, and the organic layers were washed with saturated brine to neutrality, dried over $\mathrm{Na}_{2} \mathrm{SO}_{4}$, and concentrated to make the brown crude product, which was twice purified by recrystallization with $15 \mathrm{~mL}$ of ethanol. Brown crystal, yield of 52\%; mp: 212.2-212.5 ${ }^{\circ} \mathrm{C}$; FT-IR $(\mathrm{KBr}) \vee\left(\mathrm{cm}^{-1}\right): 3423,3388,2943$, 2891, 1588, 1447, 1255, 752; ${ }^{1} \mathrm{H}$ NMR (DMSO-d6, $300 \mathrm{MHz}$ ): 0.64 (s, 3H), 1.28-1.31 $(\mathrm{d}, 1 \mathrm{H}), 1.37(\mathrm{~s}, 3 \mathrm{H}), 2.30(\mathrm{~s}, 1 \mathrm{H}), 2.67-2.72(\mathrm{~m}, 1 \mathrm{H}), 2.80-2.84(\mathrm{t}, 2 \mathrm{H}), 2.92-2.97(\mathrm{~d}$, 1H), 6.84-6.92 (m, 2H), 7.11-7.16 (t, 1H), 7.16-7.53 (d, 1H), 11.69 (s, 1H), 12.67 (s, $1 \mathrm{H}) ;{ }^{13} \mathrm{C}$ NMR (DMSO-d6, $\left.75 \mathrm{MHz}\right), \delta$ (ppm): 21.17, 25.82, 26.32, 31.87, 107.79, 116.22, 117.95, 118.89, 126.85, 128.14, 155.28; EI-MS m/z (\%): $254\left(\mathrm{M}^{+}, 83\right), 239$ (58), 225 (14), 212 (18), 211 (100), 197 (24), 186 (27), 65 (9); HRMS (m/z): [M+H] calcd for $\mathrm{C}_{16} \mathrm{H}_{18} \mathrm{~N}_{2} \mathrm{O}+\mathrm{H}^{+}$, 255.1491; found, 255.1493.

\subsubsection{6,6-Dimethyl-3-(3'-hydroxyphenyl)-4,5,6,7-tetrahydro-2H-5,7-methano-indazole}

(5). A mixture of 3-(3'-hydroxybenzylidene)nopinone 2 (5 mmol), hydrazine hydrate $(6$ mmol), and ethanol (30 $\mathrm{mL})$ was refluxed for $16 \mathrm{~h}$, other conditions reference compound 4. Yellow crystal, yield of 56\%; mp: 267.2-267.4 ${ }^{\circ} \mathrm{C}$; FT-IR $(\mathrm{KBr}) \vee\left(\mathrm{cm}^{-1}\right)$ : 3426, 3286, 2981, 2944, 1621, 1571, 1225, 858, 780, 686; ${ }^{1} \mathrm{H}$ NMR (DMSO-do, 300 MHz): $0.65(\mathrm{~s}, 3 \mathrm{H}), 1.25-1.28(\mathrm{~d}, 1 \mathrm{H}), 1.38(\mathrm{~s}, 3 \mathrm{H}), 2.29(\mathrm{~s}, 1 \mathrm{H}), 2.67-2.72(\mathrm{~m}, 1 \mathrm{H})$, 2.75-2.93 (m, 3H), 6.69-6.72 (d, 1H), 7.11-7.13 (d, 2H), 7.19-7.24 (t, 1H), $9.48(\mathrm{~s}, 1 \mathrm{H})$, $12.31(\mathrm{~s}, 1 \mathrm{H}) ;{ }^{13} \mathrm{C}$ NMR (DMSO-d6, $\left.75 \mathrm{MHz}\right), \delta$ (ppm): 21.32, 26.01, 26.09, 32.12, 111.99, 114.19, 115.84, 129.77, 157.63; EI-MS m/z (\%): $254\left(\mathrm{M}^{+}, 33\right), 239$ (35), 225 (8), 212 (17), 211 (100), 186 (18), 65 (8); HRMS (m/z): $[\mathrm{M}+\mathrm{H}]^{+}$calcd for $\mathrm{C}_{16} \mathrm{H}_{18} \mathrm{~N}_{2} \mathrm{O}$ $+\mathrm{H}^{+}, 255.1491$; found, 255.1492.

\subsubsection{6,6-Dimethyl-3-(4'-hydroxyphenyl)-4,5,6,7-tetrahydro-2H-5,7-methano-indazole} (6). A mixture of 3-(4'-hydroxybenzylidene)nopinone 2 (5 mmol), hydrazine hydrate (6 
mmol), and ethanol (30 mL) was refluxed for $18 \mathrm{~h}$, other conditions reference compound 4. Yellow powder, yield of 49\%; 254.4-254.8 ${ }^{\circ} \mathrm{C}$; FT-IR $(\mathrm{KBr}) \vee\left(\mathrm{cm}^{-1}\right)$ : 3305, 2972, 2928, 1614, 1577, 1524, 1440, 1269, 1247, 839; ${ }^{1} \mathrm{H}$ NMR (DMSO-do, 300 MHz): $0.64(\mathrm{~s}, 3 \mathrm{H}), 1.24-1.27(\mathrm{~d}, 1 \mathrm{H}), 1.36(\mathrm{~s}, 3 \mathrm{H}), 2.26(\mathrm{~s}, 1 \mathrm{H}), 2.65-2.70(\mathrm{~m}, 1 \mathrm{H})$, 2.73-2.79 (m, 3H), 6.82-6.85 (d, 2H), 7.50-7.53 (d, 2H), $9.58(\mathrm{~s}, 1 \mathrm{H}), 12.16(\mathrm{~s}, 1 \mathrm{H}) ;{ }^{13} \mathrm{C}$ NMR (DMSO-d6, 75 MHz), $\delta$ (ppm): 21.33, 25.83, 26.11, 32.11, 106.89, 115.59, 122.22, 126.41, 132.78, 156.68; EI-MS m/z (\%): 254 (M+, 44), 239 (39), 225 (9), 212 (18), 211 (100), 186 (23), 65 (8); HRMS (m/z): $[\mathrm{M}+\mathrm{H}]^{+}$calcd for $\mathrm{C}_{16} \mathrm{H}_{18} \mathrm{~N}_{2} \mathrm{O}+\mathrm{H}^{+}$, 255.1491; found, 255.1486.

\section{Results and discussion}

\subsection{Thermal stabilities}

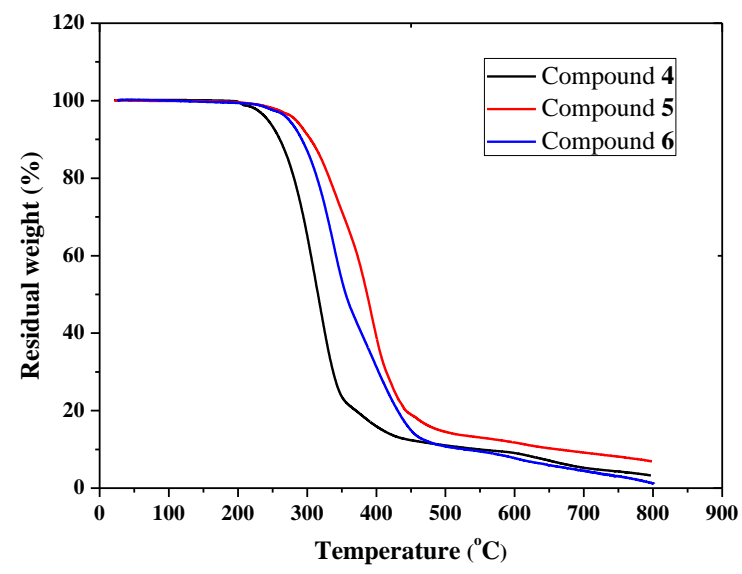

Fig. 1. TGA thermogram of pyrazole nopinone derivatives (4-6).

Good thermal stability is required for fluorescent materials, so we assessed this for compounds 4-6 using TGA under a nitrogen stream (Fig. 1). Compounds 4-6 were thermally stable up to ca. $243{ }^{\circ} \mathrm{C}, 283{ }^{\circ} \mathrm{C}$ and $274{ }^{\circ} \mathrm{C}$ and at that point $5 \%$ of the material weight was lost. Among them, compound $\mathbf{5}$ had the best thermal stability. Compounds 
4-6 would be further used as fluorescene materials because of their good thermal stability.

\subsection{HOMO and LUMO}

Highest occupied molecular orbital (HOMO) and lowest unoccupied molecular orbital (LUMO) of fluorescent compounds are important for light-emitting [29-31]. The fluorescent compound is easy to lead to electron transition when the value of band gap $(\Delta \mathrm{E}=\mathrm{LUMO}-\mathrm{HOMO})$ is very low. Thus, the value of $\Delta \mathrm{E}$ was used to study fluorescence light-emitting property of compounds 4-6, and their frontier molecular orbits had been finished by a way of computer simulation, as shown in Fig. 2.

Fig. 2 depicts the values of $\Delta \mathrm{E}$ of compounds 4-6, $6>5>4$. The pyrazole nopinone derivative with a 2'-OH group had the lowest $\Delta \mathrm{E}$ value of $4.814 \mathrm{eV}$, while another compound of 4'-OH gave a high $\Delta \mathrm{E}$ value of $5.138 \mathrm{eV}$. Comparing the structures of three compounds, only the position of $-\mathrm{OH}$ was different, that was to say that $\Delta \mathrm{E}$ was connected with the position of $-\mathrm{OH}$. The results showed that compound $\mathbf{4}$ was easy to make electron transition and emit fluorescence in compared with the other two.

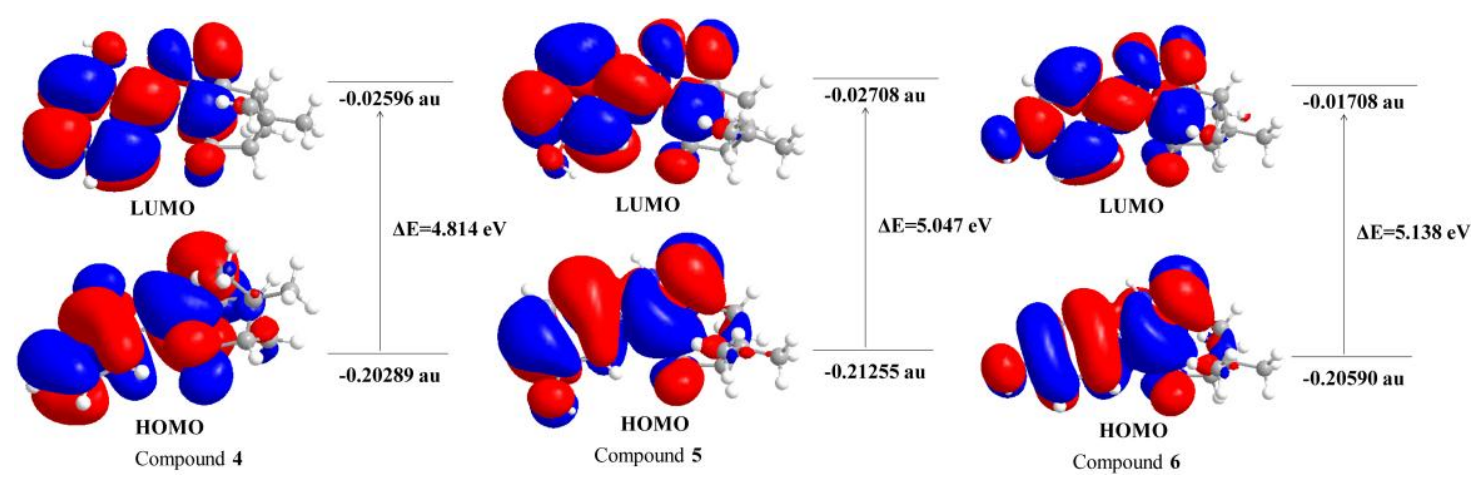

Fig. 2. Molecular orbital diagrams of HOMO and LUMO of compounds 4-6.

\subsection{Optical properties}

\subsubsection{Fluorescence properties in different solvents}


In the solution state, the fluorescence intensity is connected with solvent, and the three pyrazole derivatives (4-6) were readily soluble in some solvents, such as methanol, ethanol, isopropanol, ethyl acetate, trichloromethane, dichloromethane, toluene, cyclohexane, etc. Keeping the concentration at $1.0 \times 10^{-4} \mathrm{~mol} / \mathrm{L}$, the fluorescence spectra of compound 4 (5 or $\mathbf{6})$ in these solvents were also provided (Fig. S1, Supplementary data).

As shown in Fig. S1a, the fluorescene intensity of compound 4 was greatly affected by solvents, and it had better fluorescene after dissolution in methanol, ethanol, isopropanol or cyclohexane. Among them, compound 4 with methanol had the best fluorescence intensity. When compound $\mathbf{4}$ was respectively dissolved in dichloromethane and ethyl acetate, an obvious fluorescence quenching had happened. In addition, there was nearly no fluorescence of compound $\mathbf{4}$ in trichloromethane or toluene. Fig. S1b depicts the fluorescence spectra of compound $\mathbf{5}$ in different solvents, and the results showed that the fluorescence intensity was also concerned with the solvent. The fluorescence intensity was good and did not change when compound $\mathbf{5}$ was separately dissolved in methanol, ethanol and isopropanol. When compound $\mathbf{5}$ was dissloved in cyclohexane, ethyl acetate and dichloromethane in turn, the fuorescence intensity decreased gradually. In compared with compound $\mathbf{4}$, the solution of compound 5 in trichloromethane only had a weak fluorescence, and the fluorescence intensity was near to zero with toluene as solvent. From Fig. S1c, it was concluded that the solvent affected fluorescence of compound $\mathbf{6}$ a lot. These solvents, such as methanol, ethanol, isopropanol and cyclohexane, could enhance fluorescence and provided a good intensity, and the best solvent was ethanol. An obvious fluorescence quenching of compound 6 had happened after dissolving in ethyl acetate, while it quenched again and had a wide 
peak band when compound $\mathbf{6}$ was dissolved in dichloromethane. Fluorescence of compound 6 disappeared when trichloromethane or toluene was used as solvent. The results showed that the fluorescence intensity of compounds 4-6 was affected greatly by the solvent, and methanol, ethanol and isopropanol were suitable for using as solvents of the three compounds.

\subsubsection{Fluorescence properties in different concentrations}

The solution's concentration is also important for fluorescence light-emitting, so the fluorescence spectra of compounds 4-6 in ethanol $\left(2-20 \times 10^{-5} \mathrm{~mol} / \mathrm{L}\right)$ were fully studied, the results were shown in Fig. 3.
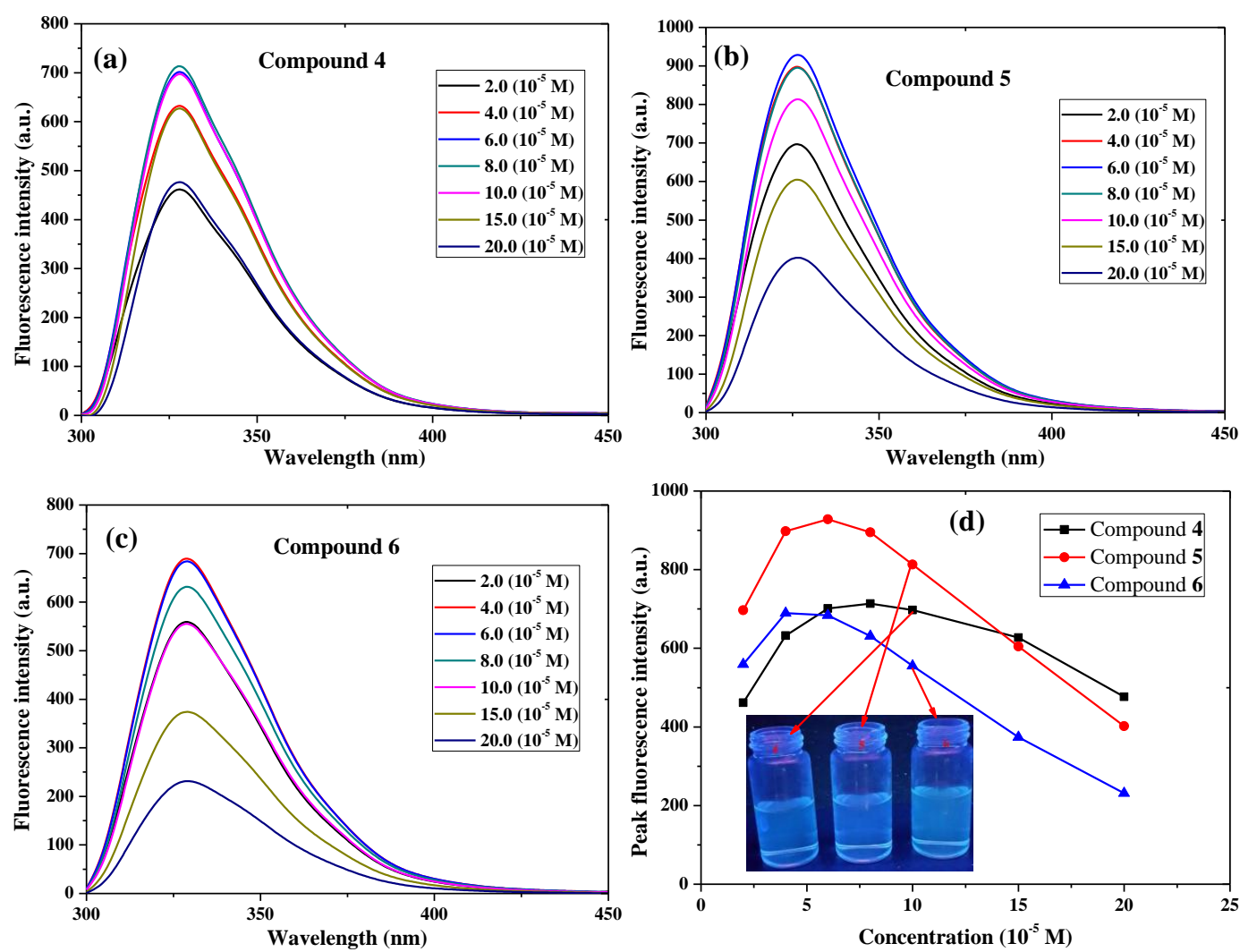

Fig. 3. Fluorescence spectra of compounds 4-6 in ethanol with different concentrations $\left(\lambda_{\mathrm{ex}}=260 \mathrm{~nm}\right)$.

As shown in Fig. 3a and Fig. 3d, the fluorescence intensity of compound $\mathbf{4}$ increased to a maximum (738.56) at the concentration of $8.0 \times 10^{-5} \mathrm{~mol} / \mathrm{L}$, then gradually decreased, 
with an increasing concentration from $10.0 \times 10^{-5}$ to $20.0 \times 10^{-5} \mathrm{~mol} / \mathrm{L}$. At the same concentration range of $2.0 \times 10^{-5}-20.0 \times 10^{-5} \mathrm{~mol} / \mathrm{L}$, the changes of fluorescence intensity of compounds 5 and $\mathbf{6}$ agreed with that of compound 4, differently, compound 5 or $\mathbf{6}$ had a maximal intensity of 862.80 or 616.27 at $6.0 \times 10^{-5} \mathrm{~mol} / \mathrm{L}$ or $4.0 \times 10^{-5} \mathrm{~mol} / \mathrm{L}$ respectively (Fig. 3b, 3c and 3d). It was concluded that the solution's concentration of compounds 4-6 affected fluorescence intensity a lot. After that, three fluorescence photographs of the three compounds in ethanol $\left(1.0 \times 10^{-4} \mathrm{~mol} / \mathrm{L}\right)$ were further provided (Fig. 3d), compounds 4-6 all had good light-emitting property and emitted strong blue light. The pyrazole derivative with a 3'-OH had the best fluorescence intensity while a 4'-OH compound gave the worst intensity in the solution state.

\subsubsection{Effect on acid-base}
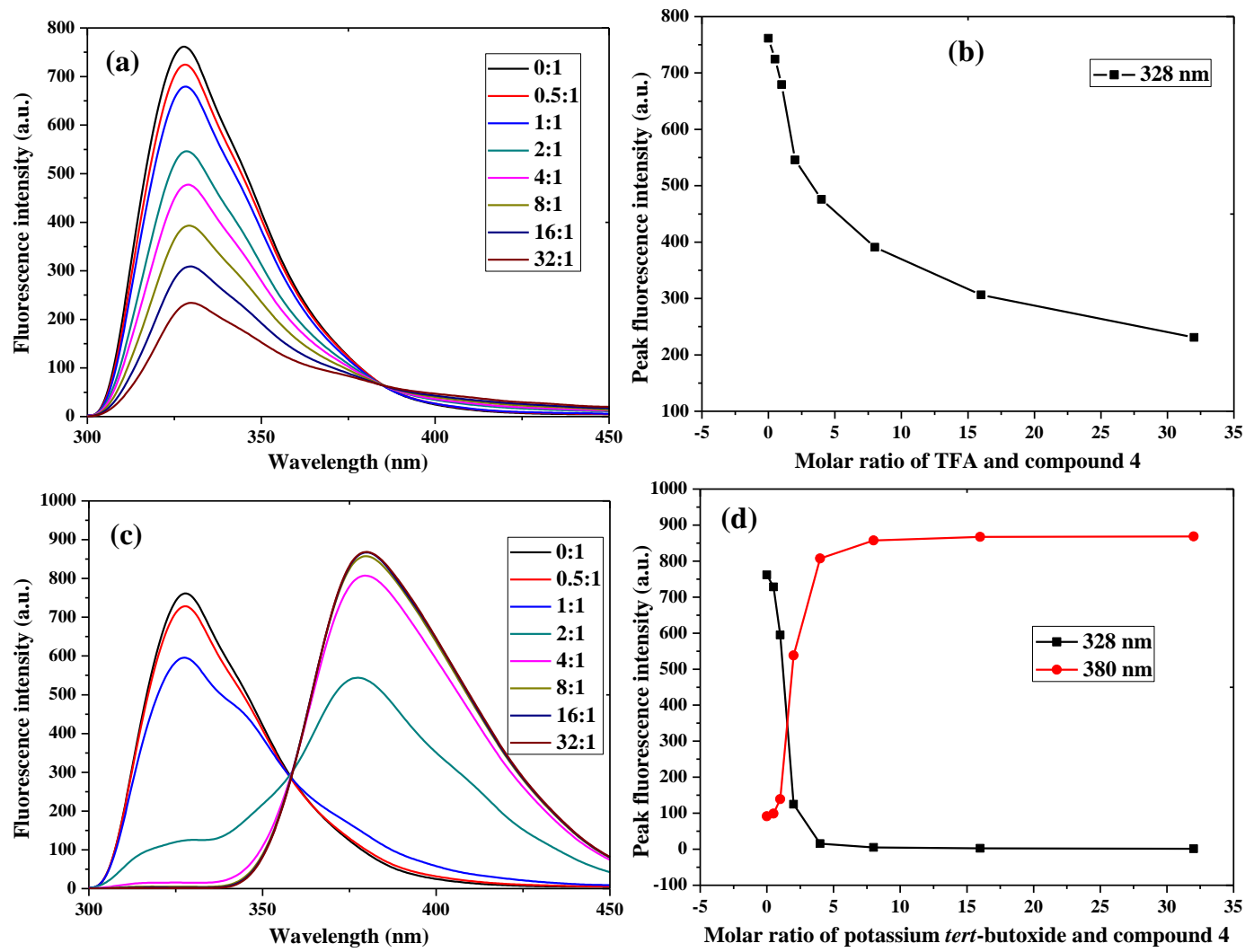

Fig. 4. Fluorescence spectral changes of compound $\mathbf{4}$ in ethanol with different molar ratios of TFA and potassium tert-butoxide $\left(\lambda_{\mathrm{ex}}=260 \mathrm{~nm}\right)$. 
Pyrazole nopinone derivatives have $-\mathrm{NH}_{2}$ and $-\mathrm{OH}$ groups, which are easy to be affected by acids and alkali, so fluorescence spectra of compounds 4-6 in ethanol $\left(1.0 \times 10^{-4} \mathrm{~mol} / \mathrm{L}\right)$ affected by trifluoroacetic acid (TFA) and potassium tert-butoxide were finished for a further study (Fig. 4, 5, 6).

Fig. $\mathbf{4 a}$ and $\mathbf{4 b}$ depict the fluorescence spectra of compound $\mathbf{4}$ with different amount of TFA, and the fluorescence gradually quenched with an increased amount of TFA. The fluorescence intensity dropped quickly when $0.5-2$ equiv of TFA was gradually added to the solution, then decreased slowly when TFA was continously added. The results showed that the addition of TFA could quench fluorescence of compound 4 in the solution state, more TFA led to more fluorescence quenching. From Fig. $4 \mathbf{c}$ and $\mathbf{4 d}$, it was clear to see that potassium tert-butoxide could make a significant changes of fluorescence spctra of compound $\mathbf{4}$ in ethanol. Without potassium tert-butoxide, a peak with high intensity appeared at $328 \mathrm{~nm}$, but the intensity decreased when the solution was gradually added an enhanced potassium tert-butoxide, and it quenched fully with more than 4.0 equiv of potassium tert-butoxide added. At the same time, there was a rised intensity appeared at $380 \mathrm{~nm}$ when the solution of compound $\mathbf{4}$ was also in the presence of equal potassium tert-butoxide. When the concentration of potassium tertbutoxide was added to $2.0 \times 10^{-4} \mathrm{~mol} / \mathrm{L}$, an obvious peak appeared at $380 \mathrm{~nm}$ with good fluoresence intensity. After that, the fluorescence intensity $(380 \mathrm{~nm})$ enhanced to a maximal step by step with an increasing amount of organic alkali until 8.0 equiv was added. Finally, potassium tert-butoxide enhanced fluorescence intensity at $380 \mathrm{~nm}$, which was more than the intensiy at $328 \mathrm{~nm}$. It was concluded that a large number of potassium tert-butoxide could quench fluorescene at $328 \mathrm{~nm}$ and enhanced fluorescene at $380 \mathrm{~nm}$. 

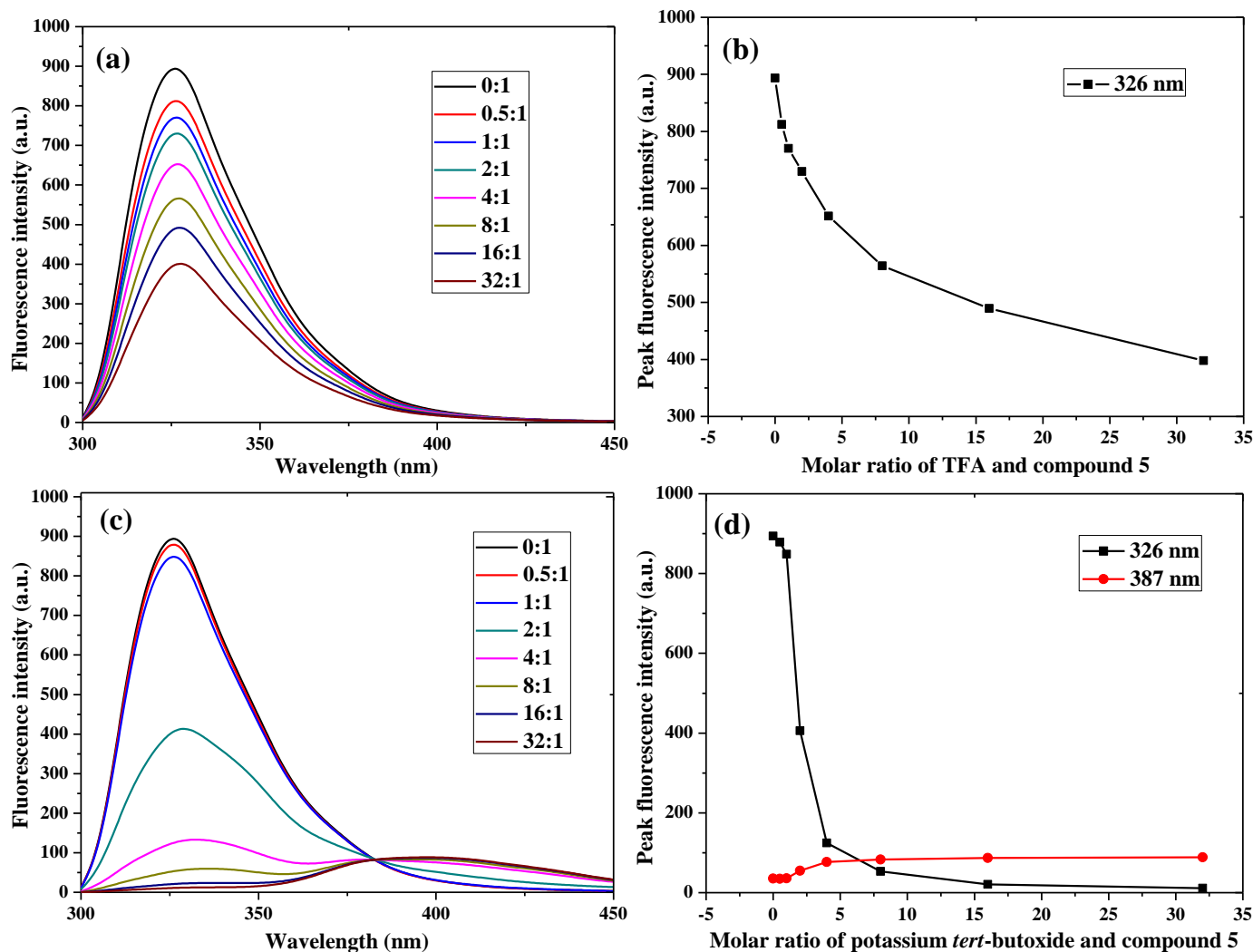

Fig. 5. Fluorescence spectral changes of compound $\mathbf{5}$ in ethanol with different molar ratios of TFA and potassium tert-butoxide $\left(\lambda_{\mathrm{ex}}=260 \mathrm{~nm}\right)$.

As shown in Fig. 5a and 5b, the compound 5's results affected by TFA agreed with that of compound $\mathbf{4}$, the fluorescence intensity gradually cut down with a rising TFA. That was to say that much TFA could quench fluoresence of compound $\mathbf{5}$ in ethanol. The fluorescence intensity $(326 \mathrm{~nm})$ reduced gradually with an increased potassium tert-butoxide, it agreed with that of compound 4. However, the addition of potassium tert-butoxide could not enhance fluorescence intensity of compound $\mathbf{5}$ in solution, which was different from that of compound 4. Although a new peak with slight intensity appeared at $387 \mathrm{~nm}$ when 4.0 equiv of potassium tert-butoxide was added, there was no obvious fluorescence enhancement happened. It was concluded that the addition of TFA or potassium tert-butoxide could lead to fluorescence quenching of compound $\mathbf{5}$ in the solution state. 

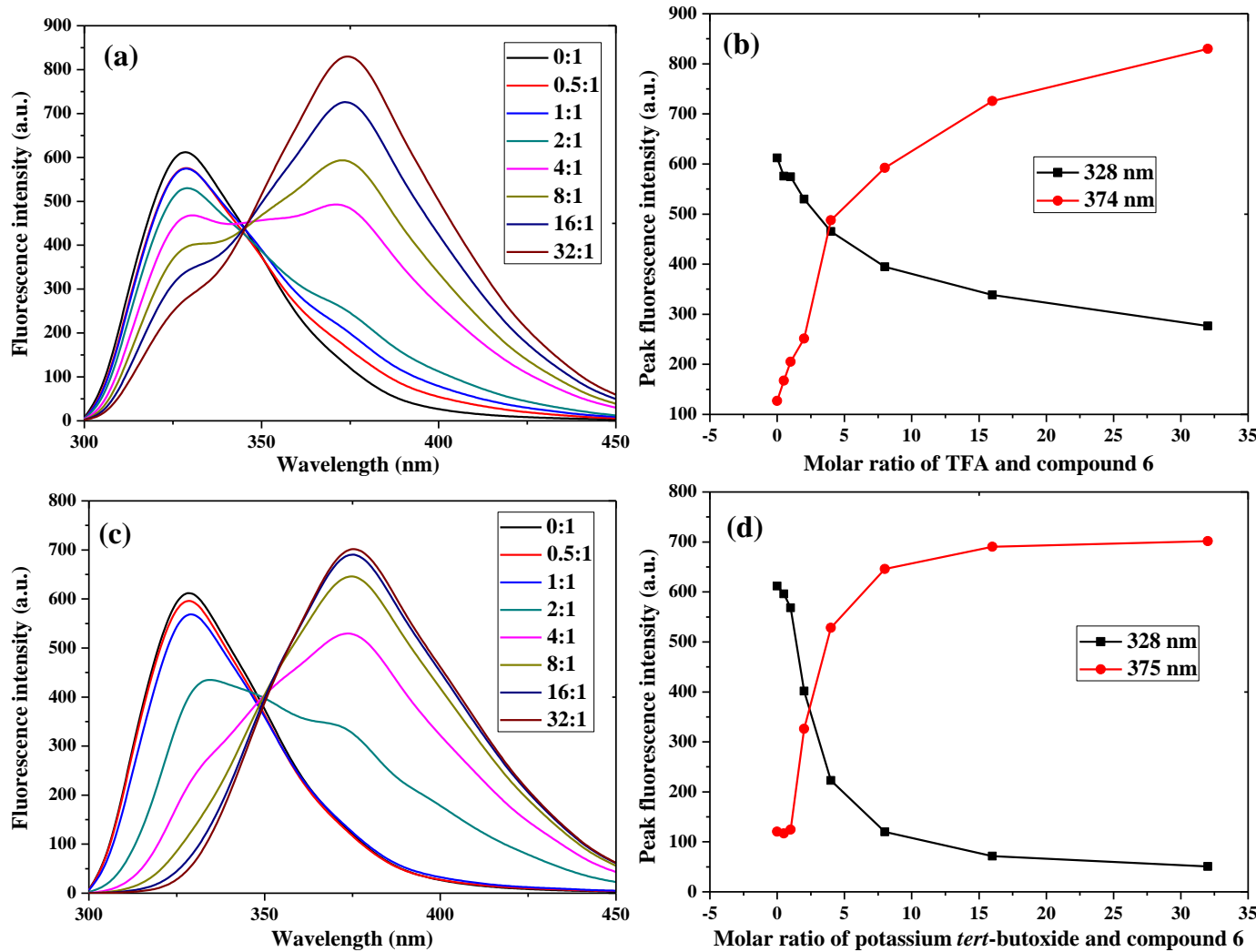

Fig. 6. Fluorescence spectral changes of compound $\mathbf{6}$ in ethanol with different molar ratios of TFA and potassium tert-butoxide $\left(\lambda_{\mathrm{ex}}=260 \mathrm{~nm}\right)$.

Fig. 6a and $\mathbf{6 b}$ depict the fluorescence spectra of compound $\mathbf{6}$ affected by TFA, which did not agree with that of compound $\mathbf{4}$ and $\mathbf{5}$. The fluorescence intensity of 328 $\mathrm{nm}$ peak gradually decreased when TFA was continously added to compound 6's solution, but it reduced more slowly than that of the other two. There was two peaks appeared at $328 \mathrm{~nm}$ and $374 \mathrm{~nm}$ when the molar ratio of TFA and compound 6 was 2:1. When the molar ratio of TFA and compound 6 increased to 4:1, the two peaks were very clear, and the intensity $(374 \mathrm{~nm})$ was more strong than that of $328 \mathrm{~nm}$ peak. The continuous addition of TFA led to an decrease of fluorescene intensity at $328 \mathrm{~nm}$ peak, while it enhanced fluorescence at $374 \mathrm{~nm}$ peak. The intensity $(374 \mathrm{~nm})$ was more than that of compound 6's solution without TFA when more than 16 equiv of TFA was added. The reason was that $\mathrm{N}$ atom of compound $\mathbf{4}$ had basicity and was easy to make 
protonation after adding some TFA, which agreed with that of a benzoxazole derivative (BVDA) [32]. The results revealed that a lot of TFA could enhance fluoresence of compound $\mathbf{6}$ in the solution state. From Fig. 6c and $\mathbf{6 d}$, it could be seen that the fluoresence spectra affected by potassium tert-butoxide agreed with that of compound 4 . The fluorescence intensity $(328 \mathrm{~nm})$ quenched gradually when the light-emitting system was added with an increasing potassium tert-butoxide. A new peak appeared at $375 \mathrm{~nm}$ when the molar ratio of potassium tert-butoxide and compound 6 was $2: 1$, and the intensity increased with a rising amount of potassium tert-butoxide. With 8 equiv of potassium tert-butoxide added, the solution's fluorescence intensity (375 nm) was more than that of no potassium tert-butoxide. It told that the addition of TFA or potassium tert-butoxide led to a red-shift from $328 \mathrm{~nm}$ to $374 \mathrm{~nm}$ or $375 \mathrm{~nm}$. It also told that much TFA or potassium tert-butoxide could enhance fluorescence of compound $\mathbf{6}$ in ethanol.

The results showed that the addition of TFA or potassium tert-butoxide could significantly change the fluorescence spectra of compounds 4-6. The reason for quenching fluorescence by TFA might be a collision with $\mathrm{H}^{+}$(a proton transfer reaction in the excited state) [33]. The -OH group in compounds 4 and $\mathbf{6}$ could easily response with $\mathrm{OH}^{-}$of potassium tert-butoxide, and deprotonation occurred and led to a fluorescence enhancement [26].

\subsubsection{Spectral responses with metal ion}

In the solution state, pyrazole nopinone derivatives (4-6) had good fluorescence lightemitting function, and their $-\mathrm{NH}_{2}$ and $-\mathrm{OH}$ groups could response with some metal ions, then led to a fluorescence enhancement or quenching with a function of detecting metal ion. Thus, alkali metal ions and transition metal ions were used to study the spectral responses of compounds 4-6 $\left(1 \times 10^{-4} \mathrm{~mol} / \mathrm{L}\right)$, UV-visible absorption and fluorescence 
spectra were obtained after adding 1.0 equivalent of each metal ion, the results were shown in Fig. S2 and Fig. 7.
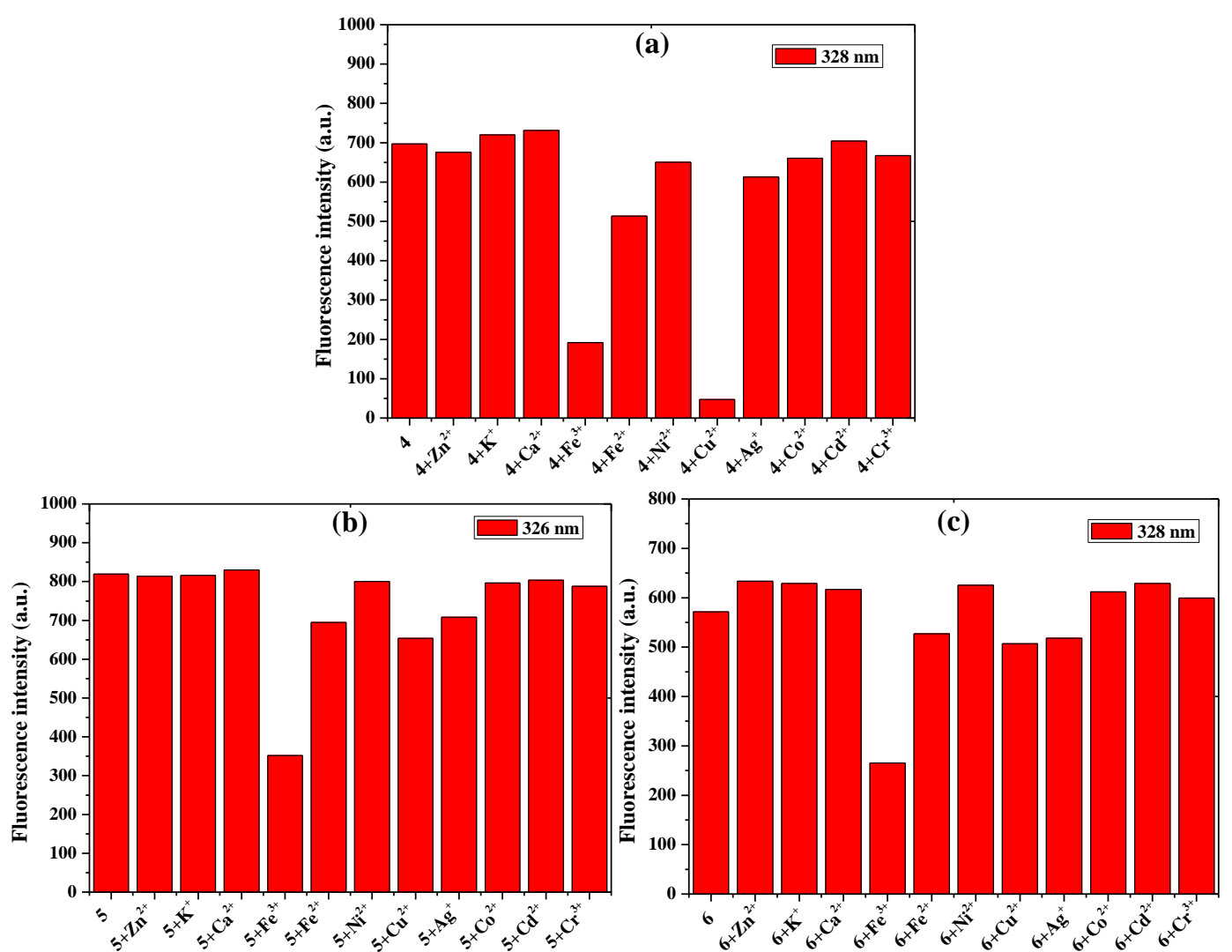

Fig. 7. Fluorescence intensity of compounds 4 (a), 5 (b) and 6 (c) in ethanol solution with equal different metal ions $\left(\lambda_{\mathrm{ex}}=260 \mathrm{~nm}\right)$.

As shown in Fig. S2a, there was an obvious changes of UV-visible absorption spectra after adding $\mathrm{Cu}^{2+}$ or $\mathrm{Fe}^{3+}$, that was to say that a response had happened between compound 4 and $\mathrm{Cu}^{2+}$ or $\mathrm{Fe}^{3+}$. Fig. 7a showed the fluorescence intensity of compound 4 in ethanol with different metal ions, and it was clear to see that the addition of $\mathrm{Cu}^{2+}$ or $\mathrm{Fe}^{3+}$ could make a significant fluorescence quenching, and $\mathrm{Cu}^{2+}$ ion quenched almost totally. It told that compound $\mathbf{4}$ had a response with $\mathrm{Cu}^{2+}$ or $\mathrm{Fe}^{3+}$, which agreed with that of Fig. S2a. The results showed that a fluorescence quenching method of compound 4 could be further used to detect $\mathrm{Cu}^{2+}$ or $\mathrm{Fe}^{3+}$. Compared with other methods, fluorescence 
quenching method is of various advantages. It is sensitive and easy and has a short analysis time [34-38].

Fig. S2b and Fig. 7b showed a response of UV-visible absorption and fluorescence spectra with one metal ion. A significant change of UV-visible absorption spectra occured when compound 5's solution was added equal $\mathrm{Fe}^{3+}$ ion (Fig. S2b), meanwhile, the addition of $\mathrm{Fe}^{3+}$ also decreased fluorescence intensity sinificantly (Fig. 7b). That was to say that only $\mathrm{Fe}^{3+}$ ion could easily interact with comound 5. As shown in Fig. S2c, the UV-visible absorption spectra of compound $\mathbf{6}$ was greatly affected by $\mathrm{Fe}^{3+}$ ion with its absorbance enhanced, which agreed with that of Fig. S2a and Fig. S2b. After analyzing Fig. 7c, the results of compound 6 affected by 11 metal ions were in accord with that of Fig. 7b, only $\mathrm{Fe}^{3+}$ ion could clearly quench fluorescence of compound $\mathbf{6}$.

In a solution state, $\mathrm{Cu}^{2+}$ ion had a function of quenching fluorescence of compound $\mathbf{6}$ and $\mathrm{Fe}^{3+}$ ion could significantly quench fluorescence of compounds 4-6. Comparing the structure of three compounds, only the position of $-\mathrm{OH}$ group changed. The $-\mathrm{NH}_{2}$ and $\mathrm{OH}$ of compound $\mathbf{4}$ was very near and easy to lead to an intramolecular interaction with a metal ion, and the $-\mathrm{OH}$ of compound $\mathbf{6}$ was far away from $-\mathrm{NH}_{2}$ and impossible to make an intramolecular interaction. Thus, it was concluded that the response of compound 4 with $\mathrm{Cu}^{2+}$ ion might be intramolecular interaction, and another response of compound 4 (5 or $\mathbf{6})$ with $\mathrm{Fe}^{3+}$ ion might be intermolecular interaction.

\subsubsection{Linearity}

To obtain a linear relation of compound 4 toward different concentrations of $\mathrm{Cu}^{2+}$ or $\mathrm{Fe}^{3+}$ for detecting the content of $\mathrm{Cu}^{2+}$ or $\mathrm{Fe}^{3+}$ in solution, we measured fluorescence spectra of compound $4\left(1 \times 10^{-4} \mathrm{~mol} / \mathrm{L}\right)$ in ethanol upon addition of various concentrations of $\mathrm{Cu}^{2+}$ or $\mathrm{Fe}^{3+}$ ion, as shown in Fig. 8a or 8c. 

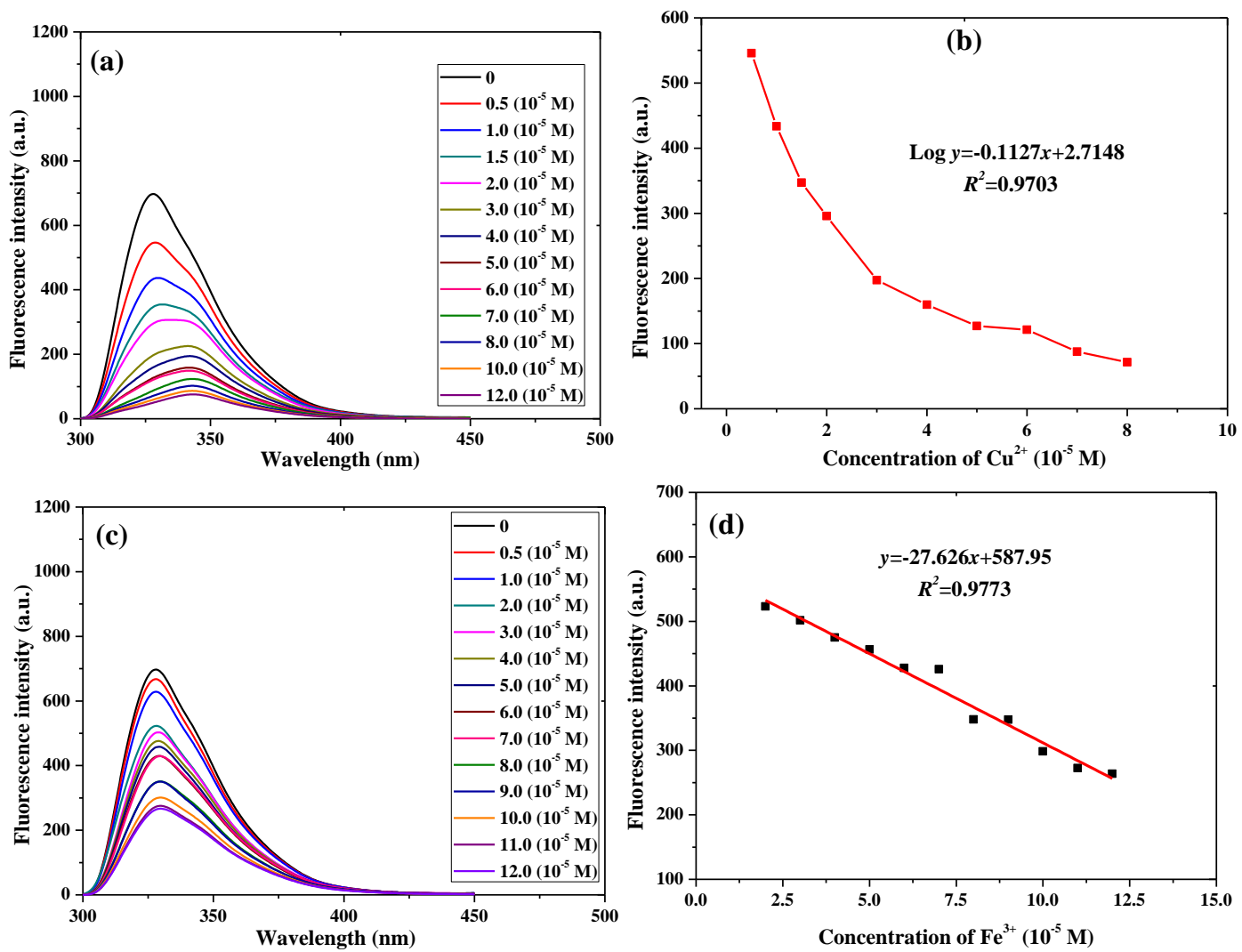

Fig. 8. Fluorescence spectral changes of compound 4 with different concentration of $\mathrm{Cu}^{2+}$ (a) and $\mathrm{Fe}^{3+}$ (c); The linear relationship between fluorescence intensity of compound 4 and $\mathrm{Cu}^{2+}(\mathrm{b})$ and $\mathrm{Fe}^{3+}(\mathrm{d})$ concentrations, $\left(\lambda_{\mathrm{ex}}=260 \mathrm{~nm}\right)$.

The fluorescence intensity of compound 4's solution decreased gradually with an increasing $\mathrm{Cu}^{2+}$ or $\mathrm{Fe}^{3+}$ ion. A relationship of peak fluorescence intensity and $\mathrm{Cu}^{2+}$ concentration was also provided in Fig. S3. Furthermore, the linear relationship of Log $\mathrm{F}$ and $\mathrm{Cu}^{2+}$ concentration $\left(0.05-0.8 \times 10^{-4} \mathrm{~mol} / \mathrm{L}\right)$ was also finished $(\mathbf{F i g} .8 \mathbf{b}), \log y=-$ $0.1127 x+2.7148, R^{2}=0.9703$. At the same time, Fig. S4a clearly depicted the relationship of peak intensity and $\mathrm{Fe}^{3+}$ concentration, and the linear relationship of intensity and $\mathrm{Fe}^{3+}$ concentration $\left(0.2-1.2 \times 10^{-4} \mathrm{~mol} / \mathrm{L}\right)$ was further provided in Fig. 8d, $y=-27.626 x+587.95, R^{2}=0.9773$. 

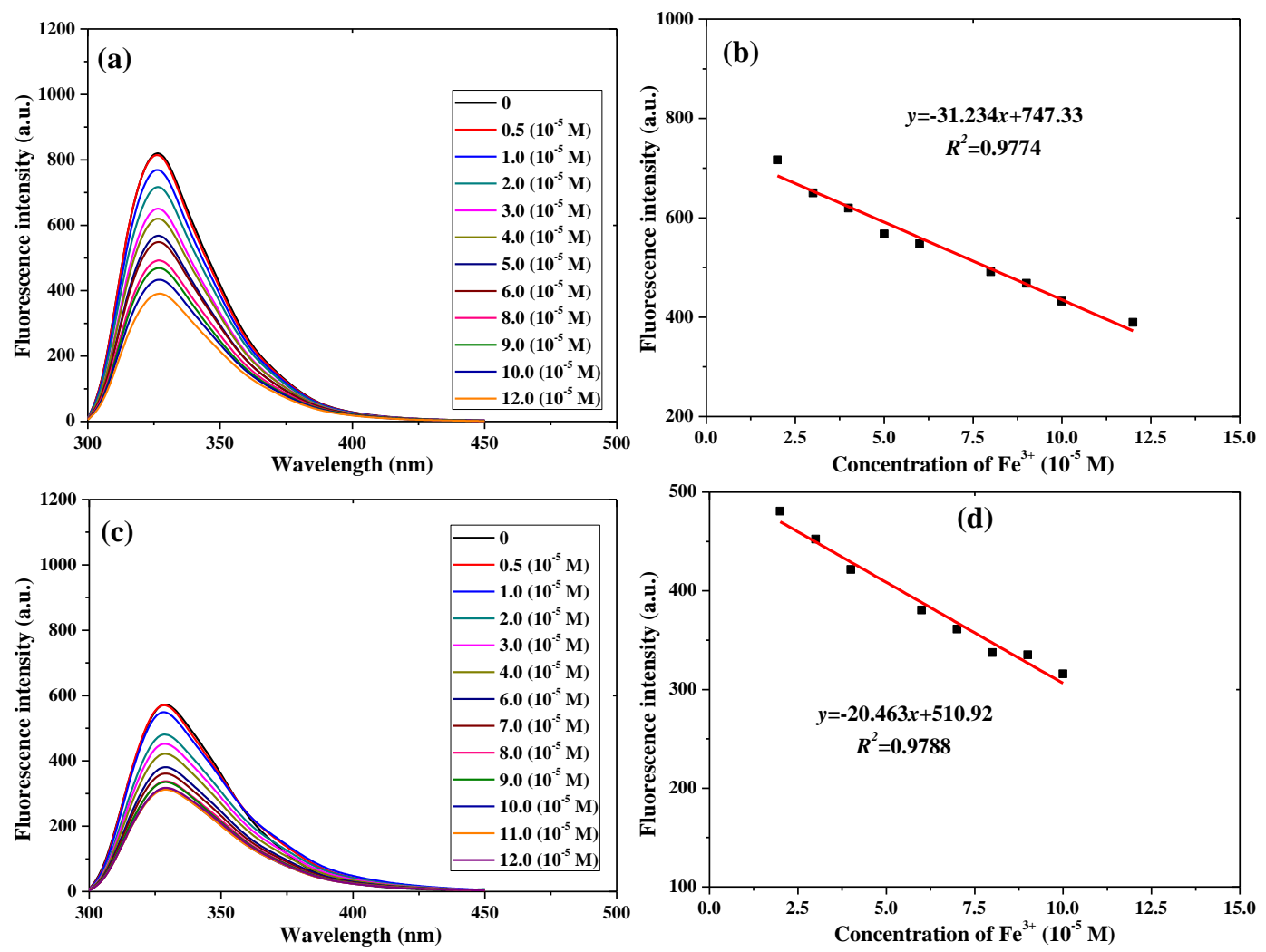

Fig. 9. Fluorescence spectral changes of compounds 5 (a) and 6 (c) with different concentration of $\mathrm{Fe}^{3+}$; The linear relationship between fluorescence intensity of compound 5 (b) or $6(d)$ and $\mathrm{Fe}^{3+}$ concentrations, $\left(\lambda_{\mathrm{ex}}=260 \mathrm{~nm}\right)$.

$\mathrm{Fe}^{3+}$ ion also had a function of quenching fluorescence of compound $\mathbf{5}$ or $\mathbf{6}$, so their fluorescence spectra with addition of different amount of $\mathrm{Fe}^{3+}$ ion had been fully studied for an application on determination of the content of $\mathrm{Fe}^{3+}$ (Fig. 9a and 9c). The peak intensiy of compound 5 or $\mathbf{6}$ reduced gradually with an rising $\mathrm{Fe}^{3+}$ concentration, the results were clearly and respectively shown in Fig. $\mathbf{S 4 b}$ and $\mathbf{S 4 c}$. After dealing with the data of Fig. S4b and S4c, a linear relation of intensity of compound 5 or 6 and $\mathrm{Fe}^{3+}$ concentration was provided in Fig. 9b or 9d, compound 5: $y=-31.234 x+747.33$, $R^{2}=0.9774\left(\mathrm{Fe}^{3+}: 0.2-1.2 \times 10^{-4} \mathrm{~mol} / \mathrm{L}\right)$; compound 6: $y=-20.463 x+510.92, R^{2}=0.9788$ $\left(\mathrm{Fe}^{3+}: 0.2-1.0 \times 10^{-4} \mathrm{~mol} / \mathrm{L}\right)$. 
In conclusion, compound 4 was a fluorescence probe for detecting the content of $\mathrm{Cu}^{2+}$ or $\mathrm{Fe}^{3+}$ in ethanol with a wide range, while compounds 5 and $\mathbf{6}$ could be used to know the concentration of $\mathrm{Fe}^{3+}$ ion by a fluorescence quenching method in a wide range.

\subsubsection{Determination of the content}

In order to make use of compounds 4-6, the contents of copper sulfate pentahydrate and anhydrous ferric chloride (purchased from the supplier) were detected for a further study, the results were shown in Table S1 and Table 1. The content was calculated after measuring the peak fluorescence intensity of each sample. The measured content of copper sulfate pentahydrate was $100.57 \%(\geq 99 \%)$ with a RSD of $1.98 \%$, and anhydrous ferric chloride was detected to provide contents of $98.56 \%$ (compound 1), $97.57 \%$ (compound 2) and 98.75\% (compound 3). The linear relationships of three compounds were successfully used to measure the content of some products.

Table 1 Determination of the content.

\begin{tabular}{ccccc}
\hline \multirow{2}{*}{ Compound } & Sample for detection & $\begin{array}{c}\text { Content found } \\
(\%)\end{array}$ & Average (\%) & RSD (\%) \\
& Copper sulfate pentahydrate & 101.97 & & \\
& $(\geq 99 \%)$ & 99.16 & 100.57 & 1.98 \\
$\mathbf{4}$ & Anhydrous ferric chloride & 97.95 & & \\
& $(\geq 97 \%)$ & 99.17 & 98.56 & 0.88 \\
& Anhydrous ferric chloride & 97.07 & & \\
& $(\geq 97 \%)$ & 98.07 & 97.57 & 0.73 \\
& Anhydrous ferric chloride & 98.21 & & \multirow{2}{*}{0.77} \\
& $(\geq 97 \%)$ & 99.29 & 98.75 & \\
\hline
\end{tabular}




\section{Conclusion}

Pyrazole derivatives (4-6) were successfully synthesized from nopinone, and their optical properties were further studied. Compounds 4-6 exhibited fluorescence enhancement phenomenon and emitted strong blue light in ethanol. The addition of TFA could enhance fluorescence of compound 6 at $374 \mathrm{~nm}$, and it increased the fluorescence intensity when the solution of compound $\mathbf{4}$ or $\mathbf{6}$ was added with much potassium tert-butoxide. In a solution state, $\mathrm{Cu}^{2+}$ ion could lead to a sinificant fluorescence quenching of compound $\mathbf{4}$, while $\mathrm{Fe}^{3+}$ ion could quench fluorescence of compounds 4-6 respectively. A good linear relationship was obtained that compound 4 could detect the content of $\mathrm{Cu}^{2+}$ from 0.5 to $8.0 \times 10^{-5} \mathrm{~mol} / \mathrm{L}(y=-0.1127 x+2.7148$, $\left.R^{2}=0.9703\right)$. At the same time, compounds 4-6 also had a function of detecting $\mathrm{Fe}^{3+}$ concentration at a wide range. Then the three fluorescent compounds were separately used to detect the content of copper sulfate pentahydrate or anhydrous ferric chloride for a better results. These properties make the new functional nopinone derivatives very competitive emitters for fluorescence detection, and it promotes the value of turpentine.

\section{Acknowledgements}

The authors gratefully acknowledge the project supported by the University Science Research Project of Jiangsu Province (14KJA220001), and the Committee of National Science Foundation of China (Grant No. 31470592). 


\section{References}

[1] Y. Wang, H.Q. Chang, W.N. Wu, X.L. Zhao, Y. Yang, Z.Q. Xu, Z.H. Xu, L. Jia, Sensor. Actuat. B Chem. 239 (2017) 60-68.

[2] Y. Hu, F. Zhao, S.L. Hu, Y.Y. Dong, D.Z. Li, Z.H. Su, J. Photochem. Photobio. Achem. 332 (2017) 351-356.

[3] P.A. More, G.S. Shankarling, Sensor. Actuat. B Chem. 241 (2017) 552-559.

[4] M.M. Yu, W.W. Du, W. Zhou, H.X. Li, C.X. Liu, L.H. Wei, Z.X. Li, H.Y. Zhang, Dyes Pigments 126 (2016) 279-285.

[5] H.Q. Chang, X.L. Zhao, W.N. Wu, L. Jia, Y. Wang, J. Lumin. 182 (2017) 268-273.

[6] H.E. Jiang, Z.J. Li, Y.F. Kang, L.P. Ding, S. Qiao, S.T. Jia, W.F. Luo, W.S. Liu, Sensor. Actuat. B Chem. 242 (2017) 112-117.

[7] Y. Wang, Z. Liu, J.H. Sun, X.G. Liu, M.S. Pei, G.Y. Zhang, J. Photochem. Photobio. Achem. 332 (2017) 515-520.

[8] B. Zhao, T. Liu, Y. Fang, L.Y. Wang, B. Song, Q.G. Deng, Tetrahedron Lett. 57 (2016) 4417-4423.

[9] Y.W. Ma, T.H. Leng, Y.R. Qu, C.Y. Wang, Y.J. Shen, W.H. Zhu, Tetrahedron 73 (2016) 14-20.

[10] Y. Yang, C.Y. Gao, N. Zhang, D.W. Dong, Sensor. Actuat. B Chem. 222 (2016) 741-746.

[11] N.V. Ghule, R.S. Bhosale, A.L. Puyad, S.V. Bhosale, S.V. Bhosale, Sensor. Actuat. B Chem. 227 (2016) 17-23.

[12] E. Şenkuytu, E.T. Eçik, M. Durmuş, G.Y. Çiftçi, Polyhedron 101 (2015) 223-229.

[13] B. Liu, W.W. Ao, Y. Yang, S.F. Wang, J. Nanjing Forest. Univ. 34 (2010) 89-94.

[14] T. Szuppa, A. Stolle, B. Ondruschka, W. Hopfe, Chem. Sus. Chem. 3 (2010) 11811191.

[15] A. Stolle, Eur. J. Org. Chem. 44 (2013) 2265-2278.

[16] M. Kato, M. Watanabe, B. Vogler, Y. Tooyama, A. Yoshikoshi, J. Chem. Soc. Chem. Commun. 23 (1990) 1706-1707.

[17] M. Watanabe, B.Z. Awen, M. Kato, J. Org. Chem. 58 (1993) 3923-3927.

[18] C.T. Goralski, W. Chrisman, D.L. Hasha, L.W. Nicholson, P.R. Rudolf, D. Zakett, B. Singaram, Tetrahedron- Asymmetr. 8 (1997) 3863-3871.

[19] E. Mena, P. Van De Witte, J. Lub, Liq. Cryst. 27 (2000) 929-933.

[20] K.R. Campos, S. Lee, M. Journet, J.J. Kowal, D. Cai, R.D. Larsen, P.J. Reider, Tetrahedron Lett. 43 (2002) 6957-6959. 
[21] R.L. Halterman, L.D. Crow, Tetrahedron Lett. 44 (2003) 2907-2909.

[22] R.C. da Silva Junior, V.F. Ferreira, S. Pinheiro, Tetrahedron-Asymmetr. 15 (2004) 3719-3722.

[23] A.V. Malkov, A.J.P. Stewart-Liddon, F. Teplý, L. Kobr, K.W. Muir, D. Haigh, P. Kočovský, Tetrahedron 64 (2008) 4011-4025.

[24] Z. Szakonyi, T. Gonda, S.B. Oetvoes, F. Fueloep, Tetrahedron-Asymmetr. 25 (2014)1138-1145.

[25] Q. Zhang, Z.B. Ding, N. Sun, X. Xu, C.F. Gao, S.F. Wang, J. Forest. Eng. 2 (2017) 51-56.

[26] J.L. Yang, X. Xu, Y.Q. Yang, J. Rui, Y. Zhang, H.B. Kuang, S.F. Wang, L.R. Wu, RSC Adv. 6 (2016) 111760-111766.

[27] J.L. Yang, H.J. Xu, X. Xu, J. Rui, X.Y. Fang, X.Q. Cao, S.F. Wang, Dyes Pigments 128 (2016) 75-83.

[28] J.L.Yang, H. Fang, X.Y. Fang, X. Xu, Y.Q. Yang, J. Rui, C.L. Wu, S.F. Wang, H.J. Xu, Tetrahedron 72 (2016) 4503-4509.

[29] F.I. Wu, P.I. Shih, M.C. Yuan, A.K. Dixit, C.F. Shu, Z.M. Chung, E.W.G. Diau, J. Mater. Chem. 15 (2005) 4753-4760.

[30] W. Wan, H. Du, J. Wang, Y. Le, H. Jiang, H. Chen, S. Zhu, J. Hao, Dyes Pigments 96 (2013) 642-652.

[31] F. Xu, H. Wang, X. Du, W. Wang, D.E. Wang, S. Chen, X. Han, N. Li, M.S. Yuan, J. Wang, Dyes Pigments 129 (2016) 121-128.

[32] P. Xue, B. Yao, J. Sun, Z. Zhang, K. Li, B. Liu, R. Lu, Dyes Pigments 112 (2015) 255-261.

[33] A.G. Bracamonte, A.V. Veglia, J. Photoch. Photobio. Achem. 261 (2013) 20-25.

[34] O. Duman, S. Tunc, B.K. Bozoglan, Journal of Fluoresc. 23 (2013) 659-669.

[35] S. Tunc, A. Cetinkaya, O. Duman, J. Phochem. Photobiol. B 120 (2013) 59-65.

[36] B.K. Bozoglan, S. Tunc, O. Duman, J. Lumin. 155 (2014) 198-204.

[37] S. Tunc, O. Duman, I. Soylu, B.K. Bozoglan, J. Lumin. 151 (2014) 22-28.

[38] S. Tunc, O. Duman, I. Soylu, B.K. Bozoglan, J. Hazard. Mater. 273 (2014) 36-43. 


\section{Graphical Abstract:}

Synthesis, optical properties and application of a set of novel pyrazole nopinone derivatives

Jinlai Yang ${ }^{\text {a,b,c }}, \mathrm{Xu} \mathrm{Xu}{ }^{\text {a,d }}$, Jian Rui a , Zhonglong Wang a , Yan Zhang ${ }^{\text {a }}$, Shifa Wang ${ }^{\text {a,d,*, }}$ Liangru $\mathrm{Wu}^{\mathrm{b}, \mathrm{c}, *}$
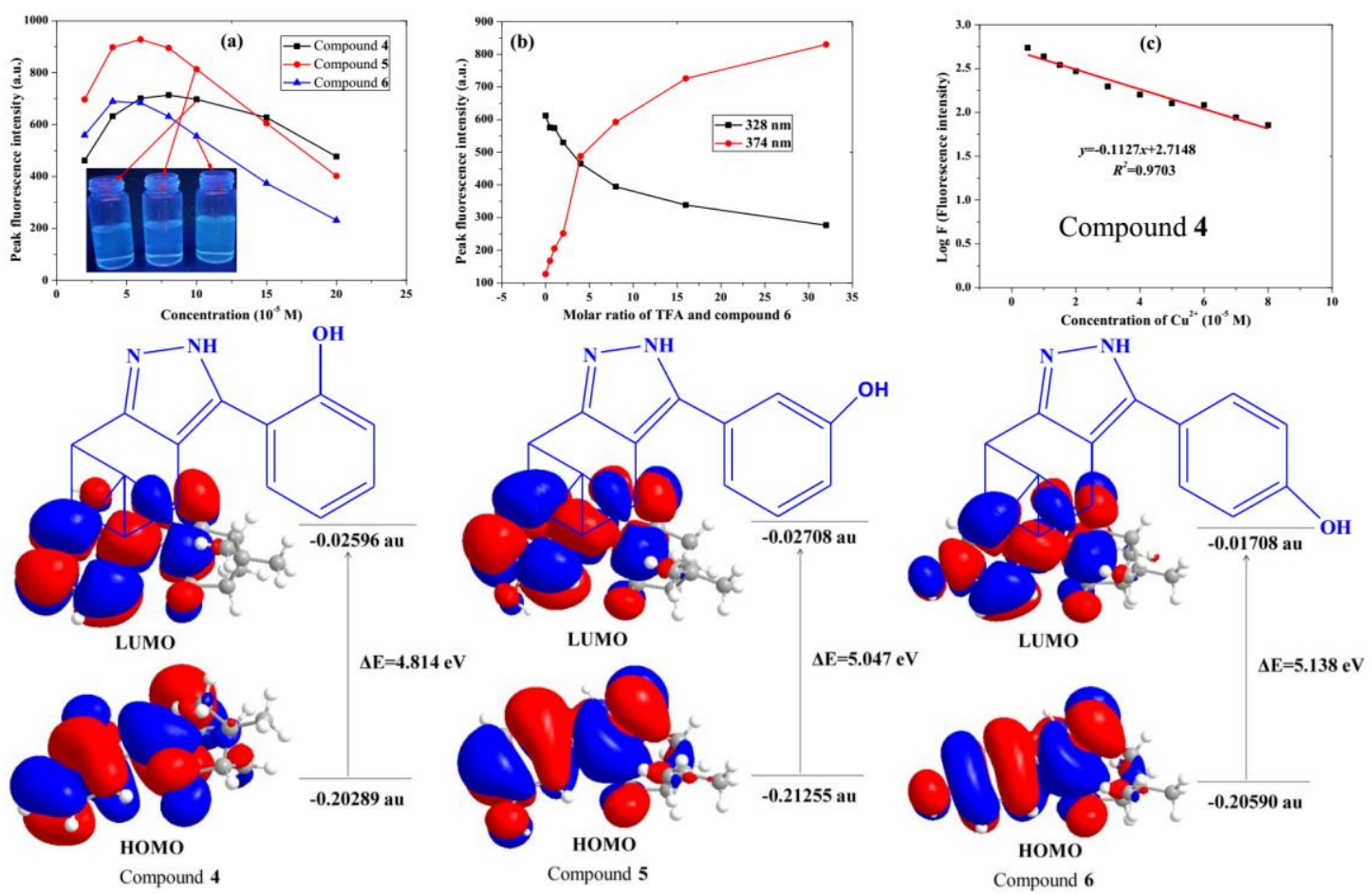